\title{
On the internal control of mandating companies with the stress on effectiveness and efficiency factors
}

\author{
Vahideh Tabibi Rad, Khadijeh Ghasemi \\ Member of the faculty, Islamic Azad university, Saveh Branch \\ M.A. in accounting, university instructor, Islamic Azad university, Saveh Branch auditor and BehboudArgham \\ auditing institute \\ The research is financed by Azad university, Saveh Branch, Saveh,Iran
}

\begin{abstract}
Many people regard the term "Internal Control" as a measure taken by the business unit to prevent from the employees' fraud. However, such measures constitute a very small part of internal controls. The main purpose of internal controls is improving the efficiency and the effectiveness of the business units operations.

Internal controls include the plans required for development, evaluation and distribution of reports by different levels of supervision, the analysis of which enables the managers to keep their controls over types of activities done in large business units.

Internal control is not confined to accounting and finance, but using budgeting methods, production standards, lab inspections, time- measuring and movement - measuring of engineers and technicians, too, are in a part of a mechanism being regarded as internal control. In this study, we have tried to analyze the internal control status of manufacturing companies of Kaveh Industrial Town, stressing on effectiveness and efficiency factors. Based on this study, the main objectives of internal controls are as follows: 1. Effectiveness and efficiency of operation, 2. Reliability of the financial reporting, 3. Following operational laws and regulations. The present study is a surveying investigation and a questionnaire in-writing has been used to collect data. Two main questions have been raised in this study: Do manufacturing companies appropriately use internal controls? And do internal controls relate to features such as education level, the field of study and the work record of the financial manager as well as the type and the side of the Co.? The findings of the study show that at the present, the manufacturing companies are mostly poor in establishment of standards and application of appropriate instructions. Also, many of them have had poor performance in establishment of functions such as responsiveness to customers, research and development, etc. Also, among the criteria, only a correlation exists between the field of study and educational level on the one hand and internal control, on the other hand

Keywords: internal controls, efficiency and effectiveness, weak points
\end{abstract}

\section{Introduction}

The committee of sponsoring organization (COSO), consists of American Accountants Association, American Official Accountants Association, Internal Accountants Association, Management Accountants'Association and the Financial Executive Managers Association. In 1994, it published the findings of the study on definition and design of internal control systems and provides solutions for evaluation of the internal control system. That report, as a source for evaluation of internal controls, was accepted extensively by professional associations. The study took three years to complete and consisted of tens of thousands research, discussion and analysis in addition, in preparation of the report, hundreds of members of the five organizations members of the committee executives of organizations, members of the boards of directors of companies, lawmakers, police officers, lawyers, consulters, auditors, and university teachers participated. That report, in addition to discussing the responsibilities of the people in correct implementation of financial controls, explores all controls that the management uses for the desirable management of the Co.

The public Audit Department of New York (2004), defines internal control as follows: "Integration of activities, plans, attitudes, policies and efforts of the individuals working in an organization to achieves its objectives and its mission.

\section{Lander (2004, p.15), defined internal control as follows:}

A process designed by executives and financial officers of the Co. or supervised by them, which is deployed by the board of directors, the management and other persons so as the reliability of financial reports for extra- organizational objectives, considering the accepted general accounting principles are ensured.

Note that the three different definitions of internal control share in three elements:

- The internal control is a process. The common- sense says that $20 \%$ of the people in most organizations do not fraud in the Co. under any condition, $60 \%$ of them fraud if appropriate conditions are met. $20 \%$ of them fraud 
under any condition. Therefore, internal control is designed essentially for the $60 \%$ group. Since internal control is a process, therefore, under the proper conditions, it must constantly make progress and it rarely occurs that a control problem has just one solution. The accountants must use their judgment and experience in designing and implementing internal control. This process must be reviewed every now and then, so as its continuous effect is ensured.

- The internal control necessarily involves the persons in the organization: In the, COSO and Lander's definition, the internal control is the responsibility of the Board of Directors and the management. In the definition given by the New York Public Department, the more extensive expression "The individuals who are colleagues in an organization" is used. Therefore, the internal control needs discussion and evaluation during design, implementation and evaluation, since it has much behavioral effect on the organizational personnel.

- The purpose of designing internal control is a realistic assurance of achieving the goals. In the dictionary, com website, the term "Reasonable" is defined as "logically or according to the reason and common sense, in the limits of common sense, without excess and extreme, For that reason, internal control could not and ought not to be designed for $100 \%$ certainty of anything. Referring to the debates on the theoretical framework of accounting, one could say that internal control is under the cost- benefit constraint. To be beneficial, its benefit must be more than its cost.

Internal control provides a logical assurance in some common grounds such as operations, financial reporting and human behavior and it is not confined to accounting controls but include an extensive range of objectives of the board of directors and the management

\subsection{Why internal control is important?}

Certainly, one of the responses is in the objectives of the internal control .In the first declaration of COSO, internal control is defined as follows: "The process that is designed by the Board of Directors, managers and the people, to assure achievement of the objectives, efficiency and effectiveness of operations' reliability of financial reports and their observation of the binding laws and regulations". Based on this study, the main objectives of internal controls would be as follows:

1. Effectiveness and efficiency of operations

2. Reliability of the financial reporting

3. Observing operational laws and regulations

The majority of managers, stockholders, employers and the organizational boards of trustees are expecting the Co. to work the most effective and the most efficient way, so as to make sure of the reliability of financial statements and protection of assets. Beyond these objectives, the internal control is mandatory according to some regulations as well. The U.S. congress passed the Foreign Corruption Penal Act (FCPA) in 1977, which was developed in international form later in mid- 1970s. In some foreign countries, bribery is an acceptable method in carrying out trade. In fact, the SEC study in the 1970s showed that more than 400 U.S. companies have given bribes to the foreign officials for different reasons. Though bribery is accepted in some foreign countries, but it is not the case in the USA. For that reason, this Act (FCPA) was passed to stop such a trend in the USA and for revival of trust in the U.S. International Trade.

Based on that Act, the U.S. companies must provide internal control in their own companies to some extent. Also, based on the Act, "Nobody should knowingly attempt to destroy or prevent from Accounting internal control and nobody should knowingly modify the books, accounts and records". In this Act, also the reasonable certainty is mentioned to, and the companies that fail to observe the Act shall be subject to fine or imprisonment.

\section{2 -Sarbanes - Oxley Law}

Following various scandals in the late 20th century, the congress passed the Sarbanes- Oxley Law in 2002.sarbanz- Oxley (abbreviated: SOX) is the broadest law on accounting next to FCPA. This broad law led to extensive change in the U.S. Commercial Companies and affected the roles of management, the board of directors, independent accountants and the Auditors' committee. Some sections of SOX that relate to internal control are:

- Managers and external accountants much evaluate the internal control of the Co. each year

- The managers must do the uncovering required in reporting to SEC. the items are: personal and corporate responsibility of managers in designing and implementing internal controls, especially those related to realistic assurance of financial statements. Also, the management must disclose the information on change of internal control after the last reporting period, especially if those changes have a significant effect on financial statements. At last, the management must let the auditors and the auditing committee of the 
presidency board about the issues and weak points of the internal control.

- The management must sign the certificates and reports relating to different sections of internal control. The power to sign could not be transferred, even through powers of Attorney.

Therefore, internal control in different kinds of organization is much important. You, as a person engaged in professional accounting, are involved in the form of external auditor (independent auditor), internal auditor, controller, or consulter, in different stages of design, implementation, and evaluation of the internal control. In section 404 of the SOX Act, the increase in responsibility of managers regarding internal controls is specifically stressed. In SEC declaration, one reads: The auditors, as colleagues of the manager, can document internal controls and discuss changes in internal controls, but it is the managers who are responsible for testing internal controls and studying and developing the documentations (in fact, the final responsibility of internal controls is upon the management).

In Iran, there is no mandate for reporting internal controls on the part of authorized officials. However, it is mentioned in the auditing standard. Standard no. 5 of the board supervising auditing of companies stipulates that: the internal control auditing governing financial reporting should be integrated with the financial statements auditing, but the auditor can choose to publish a separate report of a combined one. This combined report pays attention to financial statements and the management's report of the internal controls. In this state of affairs, the sections of the auditor's report would change so as to incorporate reference to management's report of internal controls, and the auditors views about internal controls also, mention is made to the definition of internal controls governing financial reporting and the framework used for assessing them as well as the intrinsic limitations of internal control.

In this study,we just deal those aspects of internal control that, first have more influence on the operations efficiency and effectiveness and, second, prior studies have shown that manufacturing companies are poor in them. By effectiveness we mean that the board of directors and the management are sure that they are informed about the degree of achieving the operational objectives of the Co., financial statements are reliable and the relevant laws and regulations are followed.

\section{Hypotheses:}

The first hypothesis: manufacturing companies do not use appropriately the internal controls to improve their operations efficiency and effectiveness

The second hypothesis: the degree of applying internal controls and other factors (the type and the structure of the Co., and the financial manager's field of study, educational levels, etc. are related.

\section{History}

SEC believes that the management report on effectiveness of internal controls provides managers with the opportunity to access reliable financial reports. In the SECs declaration, one reads, "with binding the managers to assume responsibility concerning financial statements and internal controls during the reporting period, the investors are able to evaluate the management's performance and its commitment to responsibility. As a result, the reliability of financial statements and even other non- audited information is improved", considering the SEC implications concerning reporting of internal controls, most external investigations relate to studying the effects and consequences of these implications ,For example, Ashbough - Skaite et al (2008), found that the reports of companies that provide the reports of internal control effectiveness, have a higher quality relative to other companies and also showed that the auditing companies with a higher rank (such as BigN, Grant, Thornton, etc.), after passing of SOX, provide more details about the status of internal control of the companies under study.

In 2005, Krishnan showed that the companies that had changed their external auditors due to lack of appropriate evaluation and reporting on the status of internal controls, had a stronger auditing committee (both regarding independence and financial knowledge and information) and their internal controls are carried out more professionally and have more consolidation and power relative other companies.

In 2009, Ashbough - Skaite, Collins, kinney, showed the connection between effective internal control and low cost of equity.3 Myers, Hammersley and Shakespeare (2008) found that the market shows negative reaction to the reports containing weak points in internal controls and this means that the weakness of internal controls is effective reducing the value of companies as viewed by investors. In contrast, we have the findings of Beneish, Billings and Hodder (2008), which show that there is no relation between the reports under SOX Act that contain the degree of implementation and effectiveness of internal controls and the market reaction.

At last, Theresa F. Heary et al, in 2011, in a study entitled, "the relation between the rewards to managers and establishment of an effective internal control in the organization, found that the managers who receive their rewards based on their performance, confirm improvement in effectiveness of internal controls. 
In Iran, most studies are about assessment of the status of internal controls. Of course, HosseinZaeri, in a study conducted in 2000, has examined the status of internal controls in private, joint- stock companies. In that study, which has been conducted through "BarrasiNamehModiriat", it is shown that most weak points of internal controls relate to cash sums with $23 \%$ frequency regarding weak points. In other items, too, the companies had the highest frequencies such as: Accounts and bills receivable (14\%), fixed assets (12\%), and inventory of materials and goods $(9 \%)$.

In 1999, MostafaRezaei examined the failures in internal controls present in Iranian Aluminum Co. (public, joint- stock) and designing an internal audit system as appropriate for that Co., evaluating the status of internal control, stressing on the management and the personnel performance in different departments, paying attention to weak points of that $\mathrm{Co}$. in designing internal controls and their way of implementation. Items such as acceptation of critics by the management, presence of instructions for implementing the operations, presence of plans for different departments are among the points stressed in that study,representing the weakness of the Co.

In 1992, Reza Dowlatabadi, studied the weak points of internal controls of companies that are members of Development and renovation organization. In that study, conducted through questionnaires, the weak points of the internal controls of those companies have been analyzed, and it seems that many of items being mentioned by him in that year are correctly being provided in most companies. Items such as presence of an organization chart or provision of a statement showing a contrast between the banking data or provision of accounting data through the software are items that are treated in the present study as well, and the responses to them by almost all companies have been positive.

In his thesis in 2004, MehrdadGhadimi has studied and evaluated the effectiveness of internal controls in public companies being studied by the auditing organization.

In that thesis, auditing standards, developed by valid foreign professional associations and domestic publications concerning evaluation of internal controls have been used. The questionnaire required has been developed and distributed among the population and the findings have been analyzed. The general findings of the study showed that the Iranian auditing standards are not sufficient for evaluation of effectiveness of internal controls of public companies.

\section{The population}

This study was conducted in industrial production companies in 2011. Kavehindustrial Town is the largest Iranian Industrial Town, which incorporates about 300 active companies. The population of the study consists of production companies of that industrial town, of which 60 companies were selected for the study.

\section{Research Methodology}

The questionnaire of this study is divided into 5 parts. A series of questions such as planning time internals and / or presence of endorsed by- laws on different fields of activity and / or the presence of authorized samples were used. In this section, the general and basic items are treated in the form of 10 questions.

The next section consists of questions about the status of human resources and the salary and wage. This section has 8 questions. Then questions about management of assets and their maintenance and preservation are raised in the form of 5 questions. Questions about the inventory are 6 in number and at last, 6 questions have been raised on the variety of reports and instructions in the Co.

\section{Data collection}

Collection of data consists of two stages: Experimental and the real data. Before the investigator collects his real data, he uses experimentally the measurement instrument.Generally, the experimental data are collected in a smaller population. The investigator gets the possibility to modify and adjust the measuring instrument and gets familiar with the problems he/ she may encounter while collecting the data.

In view of the fact the method for collecting data in this study is surveying (through the questionnaire), at first, for collecting experimental data before general distribution of the questionnaire, a pre- test was conducted and the questionnaire was distributed among 5 companies. Since the results of the tests showed that the measuring instrument was valid and reliable, the final questionnaire was developed. Then, for collection of data, 40 questionnaires were distributed in- person and the investigators themselves collected them, so as to collect more responses.

\section{Validity and reliability}

The validity of the measuring instrument means to what degree it measures the trait in question.

To increase validity, one can refer to similar studies or consult authorities and experts. Also, introductory study and collecting data experimentally, before attempting the final collection of data, and evaluation of them, could be effective in increasing the validity and accuracy of the findings. In the present 
study, in the stage of collecting experimental data, the questionnaires were distributed among a number of specialists. Considering non- presentation of suggestions or cases relating to irrelevance of questions, no reason was seen concerning lack of content validity in the measuring instrument.

Also, to show the reliability of the questionnaire, Cranach's alpha coefficient was used to estimate the reliability coefficient. Cranach's alpha- coefficient is between 0 and 1, 0 showing no reliability and 1 showing full reliability. The closer it is to 1 , the higher the reliability. Thus, at first the questionnaire was distributed among a 15- member group of the sample and the Cranach alpha coefficient was computed using SPSS and the following formula:

Where $\mathrm{n}=$ the number of questions Cranach's alpha coefficient $=$ the question's standard deviation $\mathrm{S}=$ total standard deviation

The coefficient so obtained was $75 \%$, showing the good reliability of the questionnaire. The statistical instrument

In the stage of statistical test, considering the information gained from the data, the investigator tried to get the actual result and, finally, accept or reject the hypotheses. Since this study is a surveying one, a questionnaire was developed considering the Lickertscale. The points of all items were considered from very good with 5 points down to poor with 1 point. Based on this, the average points given to the questions are 3 . Then the frequencies of responses and their \% Frequency with respect to the whole group, to any option: fully, very good, down to poor in each question were computed. As a result, the views of individuals with respect to each question are specified.

Considering these percentages, the responses of the majority are specified and the require dconclusion is made. Inferential statistics has been used to analyze the hypotheses and to accept or reject the hypotheses .The single- sample t- test was used and the results were evaluated at a 95\% significance level.

Using Friedman's test, the ratings of questions as viewed by the responders are determined. Also, this test assists us in evaluation of the questions, whether the responses to questions have been different as viewed by them or they have responded uniformly to them.

\section{Testing the Hypotheses}

As said, the questions of the questionnaire are raised in the form of several sections. The first section asks about the general conditions of the organization. The following exhibit shows a part of the questions in this section.

Has the Co. a regular periodic planning?

It yes, what time internals the plans are developed?

How is the company's performance in preparing mid- term financial statements?

Has the company executive by- laws approved by the management in all its fields of activity? How is the company's performance in that regard?

For how many of manager there are authorized signature samples?

Are tax statements (up to the end of July 22) and the insurance premium payments list (at the end of each month), submitted on time?

Is the developer of lists and forms (request for purchase, the salary lists, etc.), a person other than their approver?

The results of the questionnaires show that, the companies are especially weak in accepting critics and consulting the financial affairs department, while they have a good performance regarding early submission of the insurance premium payment list. But on the whole, a mean of 3.65 and the results of the t-test show that with a probability of $95 \%$, there is a relatively good internal control in that regard.

Another section of the questionnaire treats the status of human resources and the salary and wage, an example of which is given in the following exhibit:

Is salary payment based on the inception (productivity) system?

Is overtime beyond that expected? How is the performance of the Co. in that respect?

Is the salary always being paid through an independent bank account? How is the management's performance in that respect?

Is there an appropriate by- laws for continued monitoring and periodic evaluation of the people? How is the company's performance in that regard?

The results of the analysis of questionnaires reveals the fact that the performance of companies regarding overtime is poor and it is good as regards payments of the salaries through an independent banking account. On the whole, the mean 3.55 and the t- test results show that relatively good internal controls exist in that regard with probability of $95 \%$. 
The next section relates to properties and assets. Analysis of this section is difficult due to its extension. To choose the questions in this section, more use was made of professional persons' experience and preferably those questions were chosen in which a weakness was seen. Some questions related to this section are as follows:

Has the cashier access to the auxiliary account of the customers?

- $\quad$ Have the people in charge of reception and payment of cash, given a guarantee?

- $\quad$ Is access to the salespersons list (for enquiry about the prices) confined to special persons ?

in that regard?

- Have you considered the machines that need replacement?

- $\quad$ Is the list of stagnant and low- flow inventories being prepared?

- $\quad$ Are the assets (such as securities) being properly evaluated at the end of the year?

- The results of analysis of questionnaires show that the performance of companies regarding the number of copies of forms such as warehouse receipt, drafts and the wasted time in production is poor while it is good regarding monitoring stagnant and unused assets. On the whole, a mean of 3.53 and the t-test results show that with a probability of $95 \%$, a relatively good internal control exists in that regard. In the final section, the reports and instructions as well as the limitation are questioned about.

Which of the following reports are prepared in the Co.?
$\begin{array}{ll}\text { a. Labor performance and efficiency evaluation } & \text { b. Special cases of significant deviations } \\ \text { c. \% of use of the potential of the fixed asset } & \text { d. The materials efficiency (the amount of materials } \\ \text { waste) } & \end{array}$
$\begin{array}{lll}\text { - For which of the following there is a special instruction or constraint? } \\ \text { a) The credit limit of the customers } & \text { b) } & \text { Access to accounting documents and books } \\ \text { c) Access to information systems } & \text { d) } & \text { Repair and maintenance }\end{array}$
$\begin{array}{lll}\text { - For which of the following, there is a separate section in the Co.? } \\ \text { a) Research and development } & \text { b) } & \text { Repair and maintenance } \\ \text { c) Quality control } & \text { d) } & \text { Education } \\ \text { e) After- sales services } & \text { f) } & \text { IT } \\ \text { g) Internal auditing } & \text { h) } & \text { Responding to complaints }\end{array}$

this section, the companies are weaker than in other sections. For example, in many companies, there were no spate sections for education, responding to the customers' complaints, quality control and even research and development. Some reports, such as \% of the capacity of fixed assets or special case of significant deviations are not developed and for items such as material wastes and product wastes, repair and maintenance and quality control, no instruction and standard exists. On the whole, a mean of 2.35 and the t-test results show that with a probability of $95 \%$, there is a poor internal control in that regard. However, as regards the relation between the degree of implementation of internal control and factors such as educational level, field of study and the work experience of the financial manager and other items such as the type and the size of the Co., regarding the amount of capital and the number of personnel, the correlation- test was used, the results of which are as follows:

- Considering the result of the correlation test, there was no correlation between the degree of implementation of internal controls and the work experience of the financial manager: Pearson correlation $=-0.004$

- Considering the result of the correlation test, there is a correlation between the degree of implementation of internal controls and the financial manager's field of study. The results related to the questionnaires are given in the following exhibit.

Pearson correlation $=0.62$

Also, there was a correlation between the degree of implementation of internal controls and the financial manager's educational level considering the test result.

The results relating to the questionnaires are given in the following exhibit. Pearson correlation $=0.58$

No correlation was seen between the degree of implementation of internal controls and the type of the Co. and number of its personnel. Of course, the findings show that the companies that have internal auditors, have a better internal control status than other companies 


\section{The results and suggestions}

In contrast to what that seemed true at the beginning. The work experience of financial managers and personnel had no effect on the degree of implementing internal controls. But the field of study (with the priority given to accounting) and the educational level (at graduate level) give the financial manager a better viewpoint and knowledge. Especially in what concerns effectiveness, efficiency and performance evaluation, as said before, the highest weak points concerned lack of preparation of standards and reports in different sections and items of organizations, preparation of these reports could serve both as a tracker control and as a preventive internal control as well as a factor for improving efficiency and effectiveness of operations, with improvement in the educational level of financial managers and their selection from among accounting graduates, the internal control status of the companies will improve as well. Since the internal control is one of the objectives of company's governance. Which is a current auditing topic, therefore, carrying out a correct and appropriate internal control is among important activities in the companies.

\section{References}

[1]. Apostolou, B., \& Apostolou, N. G. (1991). Managerial evaluation of the internal control structure. Research in Accounting Regulation,vol 5,121-143

[2]. Ashbaugh-Skaife (2008). A study of the relationship between company performance and CEO compensation. American Business Review, 18),77-85).

[3]. Ashbaugh-Skaife, H., Collins, D. W., Kinney, W. R., \& LaFond, R. (2009). The effect of sox internal control deficiencies on firm risk and cost of equity. Journal of Accounting Research, 47(March), 1-43.

[4]. Beneish, M. D., Billings, M. B., \& Hodder, L. D. (2008). Internal control weaknesses and information uncertainty. The Accounting Review,83(May), 665-703.

[5]. 5. Committee of sponsoring organization of the treadway commission.2002 Internal

[6]. control :Integrated framework .New York:AICPA

[7]. Dowlatabadi, Reza, 1992, on weak points of internal controls of companies that are members of the development and innovation organization, M.A. thesis, Tehran University

[8]. Ge, W., \& McVay, S. (2005). The disclosure of material weaknesses in internal control after the Sarbanes-Oxley Act. Accounting Horizons, 19(September), 137-158

[9]. Ghadimi, Mehrdad,2004, on the status of effectiveness of internal controls in public companies being studied by the auditing organization, M.A. thesis, Tehran University

[10]. Hammersley, J. S., Myers, L. A., \& Shakespeare, C. (2008). Market reactions to the disclosure of internal control weaknesses and to thecharacteristics of those weaknesses under Section 302 of the Sarbanes Oxley Act of 2002. Review of Accounting Studies, 13(March141-165.

[11]. Krishnan, J., \& Krishnan, J. (1996). The role of economic trade-offs in the audit opinion decision: An empirical analysis. Journal of Accounting,Auditing, \& Finance, 11(Fall), 565-586

[12]. Lander, G 2004.What is Sarbanes-Oxley?Newyork:McGrowhill.

[13]. Rezaei, Mostafa, 1999, Deficiencies of the internal controls present in Iranian Aluminum Co. (public, joint-stock) and design of internal auditing system, M.A. thesis, Islamic Azad University, Tehran Center Branch

[14]. Theresa F. Heary, 2011, he relation between the rewards to managers and establishment of an effective internal control in the organization

[15]. Zarei, Hossein, "on the status of internal controls in private, joint- stock companies", Hessabdar, no. 147 